\title{
Propriedade intelectual e tecnologias verdes
}

Adriana Sarra

\section{Resumo:}

Dado que as tecnologias de mitigação são fundamentais para combater as mudanças climáticas, questiona-se se os direitos de propriedade intelectual são meios eficientes de estímulo à difusão e ao desenvolvimento das tecnologias verdes. A partir da análise do estudo Patents and Clean Energy: Bridging the Gap Between Evidence and Police, concluiu-se que políticas públicas envolvendo os direitos de propriedade intelectual, embora não atuem de forma isolada, são meios eficientes de estímulo ao desenvolvimento local e à transferência de tecnologias verdes. Além disso, mostrou-se que países em desenvolvimento precisam incentivar a criação local e a transferência de tecnologias verdes. Com relação ao Brasil, constatou-se que o Projeto Patentes Verdes, proposto pelo Instituto Nacional da Propriedade Intelectual, é uma política pública que adota as visões do estudo.

Palavras-chave: tecnologias verdes - propriedade intelectual - políticas públicas 


\section{Introdução}

Embora discutido há alguns séculos, foi no final do século XI que o problema das mudanças climáticas assumiu as proporções atuais. Tornou-se uma das maiores e mais complexas preocupações do mundo, cuja superação depende de inédita mobilização de recursos, tanto financeiros quanto humanos. Nesse contexto, a inovação tecnológica será imprescindível à descoberta de novos caminhos que assegurem a sustentabilidade.

Por isso, recebem destaque as maneiras de incentivar o desenvolvimento e a difusão em larga escala tanto de tecnologias de mitigação quanto de adaptação às mudanças climáticas. As segundas são as tecnologias que reduzem a exposição ou a sensibilidade do ser humano aos impactos das alterações do clima. Já as primeiras consistem em tecnologias com potencial de reduzir a emissão de gases de efeito estufa. Trata-se das green technologies (tecnologias verdes), também denominadas eco-friendly technologies, environmentally friend tecnologies ou environmentally sound technologies (ESTs). ${ }^{\mathrm{I}}$

Tendo em vista o panorama acima descrito, este artigo tem o objetivo de analisar a influência que os direitos de propriedade intelectual podem exercer sobre o desenvolvimento e a difusão das tecnologias verdes. Para tanto, será examinado um estudo conduzido pelo Escritório de Patentes Europeu ( $E u-$ ropean Patent Office - EPO) em conjunto com o Programa das Nações Unidas para o Meio Ambiente (United Nations Environment Programme - UNEP) e o Centro Internacional para o Comércio e o Desenvolvimento Sustentável (International Center for Trade and Sustainable Development - ICTSD). Em seguida, será feita uma correlação entre as conclusões do estudo e o Projeto Patentes Verdes proposto pelo Instituto Nacional da Propriedade Intelectual (INPI). Contudo, antes de abordar o estudo do EPO, convém contextualizar os debates internacionais a respeito do meio ambiente.

I Optou-se por manter os termos em língua inglesa, pois a tradução se mostrou inadequada e imprecisa. No caso da expressão environmentally sound technologies, o Decreto n. 2.652/98, que promulga a UNFGCG no Brasil, a substituiu por "tecnologias ambientalmente saudáveis". Contudo, convém observar que o texto em língua portuguesa não é uma das versões oficiais da Convenção. 


\section{O debate sobre o meio ambiente no mundo atual}

A preocupação com a preservação do meio ambiente não é novidade, embora sua relevância tenha se acentuado a partir do fim do século XX. Ao longo dessa história, o ano de 1992 é considerado um divisor de águas, pois, a partir de então o movimento ambiental assumiu posição de destaque na agenda internacional. Entre 03 e I4 de junho daquele ano, o Rio de Janeiro sediou a Conferência das Nações Unidas sobre o Meio Ambiente e o Desenvolvimento. Também conhecida como Gúpula da Terra, ECO-92 ou Rio-92, sua importância reside no reconhecimento, pelos governos, de que o desenvolvimento sustentável é imprescindível à preservação da Terra. Além disso, o evento resultou na elaboração e adoção de vários documentos, dentre os quais um programa de ação denominado Agenda 2I e três convenções internacionais sobre meio ambiente: (i) Convenção da ONU sobre Diversidade Biológica (Convention on Biological Diversity - CBD); (ii) a Convenção Internacional de Combate à Desertificação nos Países afetados por Seca Grave e/ou Desertificação, Particularmente na África (United Nations Convention to Combat Desertification in Countries Experiencing Serious Drought and/or Desertification, Particularly in Africa - UNGCD); e (iii) a Convenção-Quadro das Nações Unidas sobre Mudança Climática (United Nations Framework Convention on Climate Change - UNFGGC). Das três convenções, a última merece especial atenção por abordar o tema das tecnologias verdes.

A UNFGGG entrou em vigor internacional no ano de 1994 e foi ratificada pela maioria dos países, inclusive o Brasil. ${ }^{2}$ Considera-se que tem um caráter pioneiro, em virtude da perspectiva sob a qual endereçou a questão das mudanças climáticas: suas disposições não se restringiram à temática ambiental e enfocaram a relação do meio ambiente com o desenvolvimento econômico. É o que norteou a fixação de "responsabilidades comuns mas diferenciadas" e a divisão dos países em três grupos com comprometimentos distintos. O primeiro é o do Anexo I, que agregou os países membros da Organização para Cooperação e Desenvolvimento Econômico (Organization for Economic Co-operation and Development - OECD) em I992 e os países com economia em transição. O segundo é o do Anexo II e reuniu os países industrializados, isto é, aqueles que eram membros da OECD em I992 e não possuíam economia em

2 Até dezembro de 20II, a UNFGGC contava com I95 partes, das quais I94 são países e uma é a União Europeia, organização de integração econômica regional. No Brasil, a Convenção foi promulgada internamente pelo Decreto n. 2.652/98. 
transição. Por fim, há os países em desenvolvimento, cujos integrantes eram os países que não faziam parte do Anexo I. Reconhecendo as características e necessidades diversas de cada grupo, estabeleceu-se a obrigação de os países industrializados fornecerem recursos aos países em desenvolvimento para que pudessem implementar as disposições da UNFGGG. Nesse sentido, tinham o dever de promover a transferência de tecnologias verdes aos países em desenvolvimento:

\section{Artigo 4}

5. As Partes países desenvolvidos e outras Partes desenvolvidas incluídas no Anexo II devem adotar todas as medidas possíveis para promover, facilitar e financiar, conforme o caso, a transferência de tecnologias e de conhecimentos técnicos ambientalmente saudáveis, ou o acesso aos mesmos a outras Partes, particularmente às Partes países em desenvolvimento, a fim de capacitá-las a implementar as disposições desta Convenção. Nesse processo, as Partes países desenvolvidos devem apoiar o desenvolvimento e a melhoria das capacidades e tecnologias endógenas das Partes países em desenvolvimento. Outras Partes e organizações que estejam em condições de fazê-lo podem também auxiliar a facilitar a transferência dessas tecnologias. ${ }^{3}$

Todavia, o passar do tempo mostrou que os países industrializados não cumpriram com sua obrigação. Assim, o assunto foi retomado em I997, durante a terceira Conferência das Partes (Conference of the Parties - COP). Desta resultou o Protocolo de Kyoto, cujas disposições vincularam os países industrializados que o ratificaram a metas de redução de emissão de gases de efeito estufa. Por isso, foi reacendido o debate sobre o dever dos países industrializados estimularem o crescimento sustentável dos países em desenvolvimento por meio da transferência tecnológica. O mesmo ocorreu dez anos mais tarde, em 2007, durante a COP I3. Nela, adotou-se o "Plano de Bali", que reforçou a importância da transferência tecnológica como forma de efetivar, a longo prazo, as disposições da UNFGCG. Nessa ocasião, houve uma polarização a respeito do papel que os

3 "Article 4.5. The developed country Parties and other developed Parties included in Annex II shall take all practicable steps to promote, facilitate and finance, as appropriate, the transfer of, or access to, environmentally sound technologies and know-how to other Parties, particularly developing country Parties, to enable them to implement the provisions of the Convention. In this process, the developed country Parties shall support the development and enhancement of endogenous capacities and technologies of developing country Parties. Other Parties and organizations in a position to do so may also assist in facilitating the transfer of such technologies.” 
direitos de propriedade intelectual podem e devem desempenhar. De um lado, os países industrializados e as associações comerciais reclamavam da falta de um ambiente propício às transferências, o qual contaria com efetiva proteção aos direitos de propriedade intelectual e incentivos ao licenciamento de patentes. Em suma, condicionaram o movimento da tecnologia ao fortalecimento do regime de tutela da propriedade intelectual. De outro lado, os países em desenvolvimento e as organizações não governamentais afirmavam que os mecanismos mediados pelo mercado ${ }^{4}$ seriam um obstáculo à transferência das tecnologias. Defendiam, desse modo, o fortalecimento de medidas de flexibilização dos direitos de propriedade intelectual, como a licença compulsória. Portanto, a acentuada polarização ideológica impediu que se alcançasse um consenso.

Em 2OII, realizou-se a COP I7 em Durban, cujo tema central foi a expiração do primeiro período do Protocolo de Kyoto no ano de 20I2. Durante a Conferência, as possibilidades de planos de ação para os próximos anos foram muito discutidas, sobretudo a elaboração de um novo acordo e a posição que os países em desenvolvimento nele ocupariam. Embora se tenha preferido prorrogar a vigência do Protocolo de Kyoto, as partes presentes concordaram que um novo acordo seria elaborado até 20I5. Além disso, pela primeira vez, um grupo de países em desenvolvimento cedeu às objeções feitas pelos países industrializados. Esses países, nos quais se incluem a China e o Brasil, reconheceram a necessidade de se subordinarem a metas de redução de emissão de gases de efeito estufa. Assim, a COP I7 alterou as perspectivas para o futuro, pois há grandes chances de o próximo acordo contemplar metas de redução obrigatórias para todos os países, ampliando o Protocolo de Kyoto. Como consequência desse novo panorama, o incentivo às tecnologias verdes torna-se prioridade para os países em desenvolvimento.

\section{Patents and Clean Energy: Bridging the Gap Between Evidence and Police}

Em abril de 2009, o EPO, o UNEP e o ICTSD anunciaram a realização de um acordo para conduzir um estudo sobre a relação entre os direitos de propriedade intelectual e as tecnologias verdes. Se é consenso que a tutela

4 Mecanismos mediados pelo mercado (market-mediated mechanisms) são uma das formas por meio das quais a transferência de tecnologia pode ocorrer e caracteriza-se pelo fato de ser uma transação revestida de forma. São exemplo o investimento estrangeiro direto, o licenciamento e as joint ventures. 
à propriedade intelectual incentiva a inovação, pairam dúvidas de que o mesmo ocorra com a transferência de tecnologia. Por isso, o motivo da pesquisa foi a falta de provas, informação e transparência que pautavam os debates sobre o tema. A ausência de imparcialidade se expressava em discursos ideológicos, abstratos e retóricos, que conduziam as negociações a um impasse. Dessa forma, os formuladores de políticas públicas não tinham fundamento para fazer escolhas informadas.

Devido a essa carência de dados confiáveis, as três organizações decidiram realizar um estudo cujo objetivo era obter evidências a respeito do papel desempenhado pelas patentes no incentivo ao desenvolvimento e à transferência de tecnologias de energia limpa aos países em desenvolvimento. A pesquisa foi estruturada em três etapas: (i) mapeamento das tecnologias de energia limpa; (ii) panorama das patentes; e (iii) questionário sobre licenciamento.

A seguir, abordaremos cada uma das três fases do projeto. De início, porém, será preciso definir alguns conceitos.

\section{III.I. Conceitos}

Como consequência do maior destaque que a temática ambiental ganhou, há alguns termos específicos que estão sempre presentes e, por isso, precisam ser compreendidos. O primeiro deles é usado para se referir a tecnologias com potencial para reduzir o desperdício e a emissão de gases estufa. Trata- se das green technologies (tecnologias verdes), que também são denominadas eco-friendly technologies, environmentally friendly tecnologies ou environmentally sound technologies (ESTs). Este último termo é o adotado pela UNFGGG para se referir às tecnologias que (i) protegem o meio ambiente; (ii) são menos poluidoras; (iii) utilizam recursos de maneira mais sustentável; (iv) reciclam/reaproveitam os resíduos e produtos que emitem; ou (v) manejam os resíduos que emitem de maneira mais aceitável do que a tecnologia que substituem. Contudo, tal conceituação recebe algumas críticas em virtude de abranger tecnologias que têm potencial para reduzir as emissões de gases de efeito estufa, embora não sejam verdadeiras tecnologias de mitigação das mudanças climáticas, como é o caso do carvão limpo. ${ }^{5}$ Espécie do gênero tecnolo-

5 Cf. Final Report: Patents and Clean Energy: Bridging the Gap Between Evidence and Police. Munique, 20IO, p. I4. Disponível em: <http://documents.epo.org/projects/babylon/eponet.nsf/o/cc5da4bi68363477 cI2577ado0547289/\$FILE/patents_clean_energy_study_en.pdf>. Acesso em: O8 jan. 2012. 
gias verdes são as tecnologias de energia limpa (clean energy technologies - CETs). Estas foram o objeto do estudo desenvolvido pelo EPO, o qual as definiu como as tecnologias de geração de energia que têm potencial para reduzir a emissão de gases de efeito estufa. ${ }^{6}$

Outro conceito que merece atenção é o de transferência tecnológica. Atualmente, esta deixou de ser considerada como a mera transmissão da tecnologia àquele que a recebe. Seu significado é mais amplo, pois consiste num processo complexo e custoso, que deve tornar o receptor capaz de compreender, implementar e replicar a tecnologia. Segundo o Painel Intergovernamental sobre Mudança do Clima, transferência de tecnologia é:

[...] um amplo conjunto de processos que abrangem o fluxo de conhecimentos especializados, experiência e equipamentos para mitigar e se adaptar às mudanças climáticas e que tem lugar entre diferentes partes interessadas, como governos, entidades do setor privado, instituições financeiras, Organizações Não Governamentais (ONGs) e instituições de pesquisa/educação. ${ }^{7}$

Passando para o plano jurídico, será preciso entender o que é uma patente e o que é o direito de prioridade. A primeira é um dos direitos de propriedade intelectual e tem por objeto uma invenção ou um modelo de utilidade. É um privilégio temporário que o Estado concede e que se caracteriza por atribuir a seu titular o direito de explorar exclusivamente uma tecnologia (BARBOSA, 2003, p. 262). Em troca, o invento (invenção ou modelo de utilidade) deve se tornar público. O pressuposto da patente é que tanto o segredo industrial quanto a concorrência desleal não contribuem para o desenvolvimento tecnológico da sociedade, motivo por que devem ser repelidos. Se de um lado o inventor terá que revelar sua criação, de outro terá a certeza de que lhe será garantido o direito de explorá-la com exclusividade por certo tempo. Findo este, a tecnologia cai em domínio público e pode ser utilizada por todos. Assim, utiliza-se o Direito como ferramenta de po-

6 "[... CETs are defined as energy generation technologies which have the potential for reducing greenhouse gas emissions" (ibidem, p. 8).

7 "[...] a broad set of processes covering the flows of know-how, experience and equipment for mitigating and adapting to climate change amongst different stakeholders such as governments, private sector entities, financial institutions, non-governmental organizations (NGOs) and research/education institutions" (cf. INTERGOVERNMENTAL PANEL ON GLIMATE GHANGE. Summary for Policymakers. Methodological and Technological Issues in Technology Transfer, 2000, p. 9. Disponível em: <http://www.ipcc.ch/ pdf/special-reports/spm/srtt-en.pdf>. Acesso em: 30 dez. 20II). 
lítica econômica, estimulando a inovação e a evolução tecnológica. Além disso, mesmo durante o período de vigência da patente, há benefícios, pois as informações tornadas públicas podem servir de base para a criação de outras tecnologias. Portanto, a patente é um direito de exclusivo com caráter funcional, ou seja, é concedida pelo Estado com o intuito de incentivar o desenvolvimento econômico e tecnológico da sociedade como um todo (ibidem, p. I9).

Todavia, por ser concedida pelo Estado, a patente é territorialmente limitada, o que motivou a celebração de inúmeros tratados internacionais. Uma das hipóteses que recebia especial atenção era a de o titular de uma patente nacional querer proteger seu invento em mais de um país. Assim, criou-se o direito de prioridade, por meio do qual um estrangeiro tem a faculdade de, dentro de certo prazo, requerer a extensão de seu direito de exclusivo em todos os demais países-parte de um ato internacional. ${ }^{8}$ Contudo, apesar do direito de o titular estrangeiro requer a tutela, não há obrigação de o outro país concedê-la. A vantagem do direito de prioridade é que a data a partir da qual se verificará a novidade do invento será a do depósito no país que concedeu a primeira patente. Em outros termos, se entre a data de depósito da primeira patente e a da reivindicação da prioridade houver outro pedido de patente para a mesma tecnologia, o pedido do estrangeiro terá prioridade.

\section{III.II. Mapeamento das tecnologias de energia limpa (CETs)}

O estudo feito pelo EPO se concentrou em uma das categorias de tecnologias verdes, que são as CETs. Todavia, não foi possível enumerá-las a partir dos sistemas de classificação até então existentes, já que eles não as agrupam em classes específicas. Dessa forma, realizou-se uma pesquisa das CETs que estavam ou em mercado ou em fase de desenvolvimento. Por fim, chegou-se a seis categorias:

8 O art. I6 da Lei da Propriedade Industrial (Lei n. 9.279/96) prevê o direito de prioridade:

"Ao pedido de patente depositado em país que mantenha acordo com o Brasil, ou em organização internacional, que produza efeito de depósito nacional, será assegurado direito de prioridade, nos prazos estabelecidos no acordo, não sendo o depósito invalidado nem prejudicado por fatos ocorridos nesses prazos". 


\begin{tabular}{ll}
\hline Energia solar & - térmica (solar thermal power) \\
& - de aquecimento e refrigeração (solar heating and cooling) \\
& - fotovoltaica (solar photovoltaic) \\
\hline Energia eólica $\quad-$ continental (onshore wind energy) & - extracontinental (offshore wind energy) \\
\hline Energia marinha (ocean energy) \\
\hline Energia geotérmica (geothermal energy) \\
\hline Energia hidráulica (hydropower) \\
\hline Energia de biomassa (biomass)
\end{tabular}

Após distribuir as CETs nas categorias acima, o EPO elaborou uma nova taxonomia para complementar o sistema Europeu de Classificação (European Classification System - ECLA). Fez uma lista com aproximadamente cinquenta campos tecnológicos, incluindo não só a tecnologia em si, mas também seus componentes, acessórios e setores de aplicação. Com base nela, reclassificou cerca de 60 milhões de patentes de vários países do mundo, as quais passaram a integrar um banco de dados público. ${ }^{9}$

O fundamento dessa decisão foi o pressuposto de que o sistema de classificação de patentes que uma instituição adota pode ser funcionalizado. Em outras palavras, uma taxonomia adequada serviria como plataforma transparente, confiável e atualizada de informações sobre tecnologias patenteadas. Assim, dados melhor organizados e mais acessíveis reduziriam os custos de pesquisa e incentivariam a atividade tanto de formuladores de políticas públicas quanto de outras partes interessadas. Porém, o próprio estudo observou que essa iniciativa do EPO é apenas um passo inicial, pois há necessidade de fazer o mesmo com as demais tecnologias verdes.

9 A nova taxonomia passou a integrar o sistema Europeu de Classificação (European Classification System - EGLA) sob o código de classe Yo2, cujo título é Technologies or Applications for Mitigation or Adaptation Against Climate Change. O banco de dados está disponível em: <http://worldwide.espacenet.com/eclasrch?classif ication $=$ ecla\&locale=en_EP\&ECLA=yO2>. Acesso em: OI jan. 2012. 


\section{III.III. Panorama das patentes de CETs}

A seguir analisaram-se as tendências no campo das CETs. Nessa fase, dados do EPO e de outros escritórios nacionais foram coletados. Para a contagem do número de patentes, aplicou-se o conceito de prioridades requisitadas. Os gráficos e tabelas elaborados compararam índices relativos a todas as tecnologias, apenas às CETs e a cada uma das classes das CETs. Também houve individualização dos números por país e por empresa. Por fim, passou-se à interpretação dos resultados.

A primeira conclusão que se buscou foi sobre a tendência geral da atividade de patenteamento no mundo. O gráfico abaixo mostra o crescimento do número de prioridades requisitadas em relação ao total do ano de I978.

Em geral, a tendência foi de aumento do número de tecnologias patenteadas em todos os setores. Isso ocorreu em virtude da internacionalização do sistema de patentes por meio da assinatura de importantes tratados internacionais, que estimularam os pedidos de extensão do privilégio.

Quanto às GETs, a mesma tendência se verificou. $O$ número de requisitos de prioridade teve forte crescimento a partir do final da década de I990.

\section{Taxa de crescimento do total de prioridades requisitadas em relação a 1978}

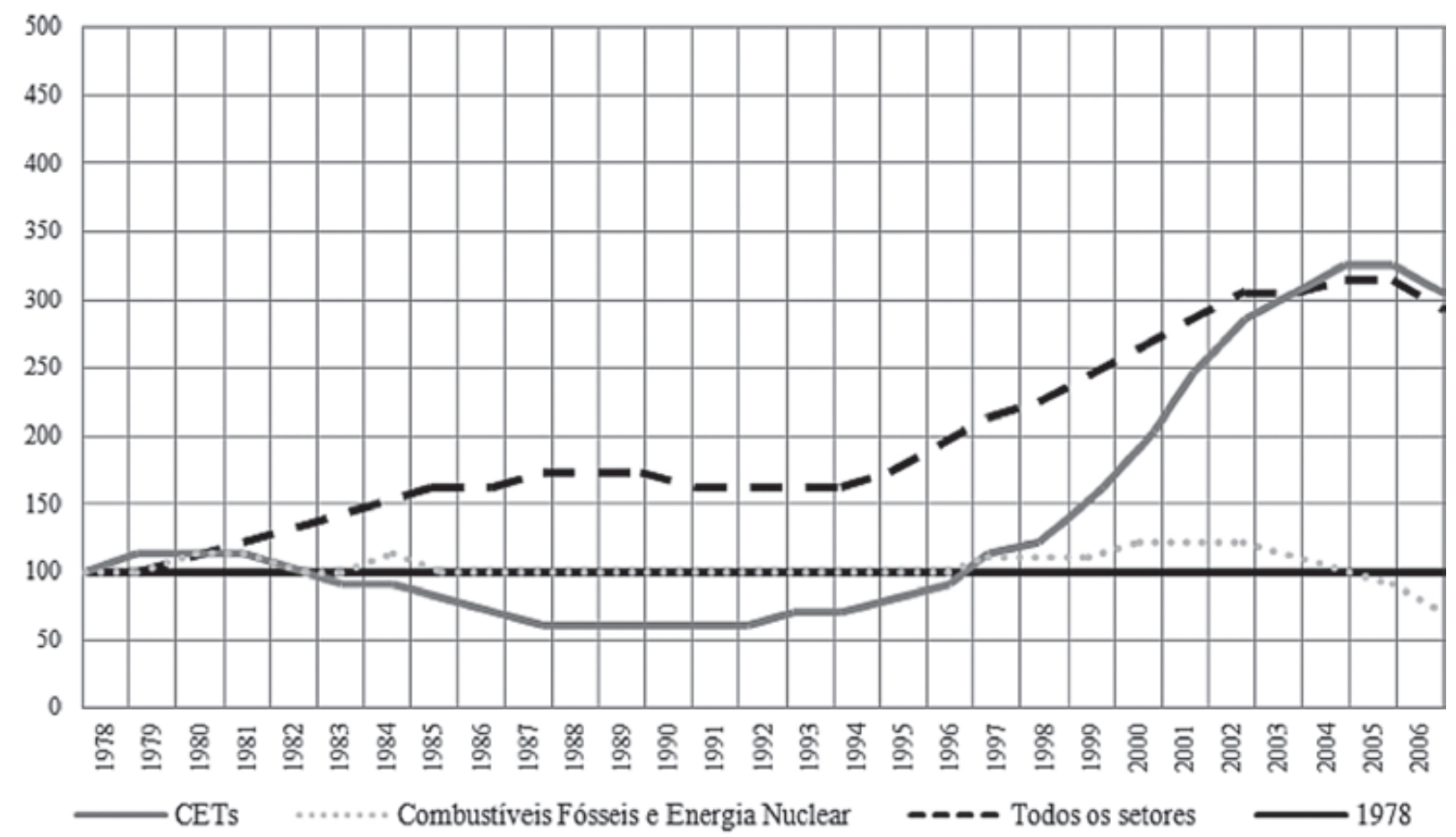

Fonte: OECD 
Além disso, se houve aceleração do ritmo de patenteamento de CETs após I997, o oposto ocorreu com as tecnologias tradicionais de geração de energia. Dentro do contexto mencionado acima, o que explica esse comportamento é a assinatura do Protocolo de Kyoto. Este colocou como prioridade o desenvolvimento de tecnologias de mitigação e vinculou os países industrializados a metas de redução da emissão de gases de efeito estufa. Foi uma interferência política no campo da inovação.

Isso nos leva a crer que políticas públicas são meios eficientes de estimular a inovação. Mas há outro elemento a ser considerado. Trata-se da influência exercida por fatores econômicos. No caso específico dos biocombustíveis, o estudo verificou que o número de prioridades requisitadas era diretamente proporcional ao preço de negociação do barril de petróleo. Ou seja, quanto mais caro este se tornava, mais interesse havia nos biocombustíveis.

O próximo passo foi verificar como se distribuía a atividade de patenteamento de 37 países. Abaixo está parte da tabela elaborada:

Número de prioridades requisitadas entre 1988 e 2007

\begin{tabular}{|r|r|r|r|r|}
\cline { 2 - 5 } \multicolumn{1}{l|}{} & \multicolumn{1}{c|}{ País } & \multicolumn{1}{c|}{ CETs } & \multicolumn{1}{c|}{$\begin{array}{c}\text { Combustíveis fósseis } \\
\text { e energia nuclear }\end{array}$} & \multicolumn{1}{c|}{ Todos os setores } \\
\hline $\mathbf{I}^{\circ}$ & Japão & 4.672 & $5.75 \mathrm{I}$ & $69 \mathrm{I} \cdot 75 \mathrm{I}$ \\
\hline $2^{\circ}$ & EUA & 2.508 & 5.543 & $423 . \mathrm{I} 87$ \\
\hline $3^{\circ}$ & Alemanha & $2.39 \mathrm{I}$ & 5.840 & $334 . \mathrm{II} 9$ \\
\hline $\mathbf{I}^{\circ}$ & China & $\mathrm{I} 43$ & $\mathrm{IO}$ & $\mathrm{I} 8.892$ \\
\hline $\mathbf{2} 5^{\circ}$ & Brasil & 24 & 30 & 2.322 \\
\hline
\end{tabular}

Fonte: OECD

Os dados não deixam dúvida de que países industrializados são os detentores da maior parte do acervo tecnológico mundial. Ainda, este se concentra em três membros da OEGD, que se alternam nas três primeiras posições: Japão, Estados Unidos e Alemanha.

Questiona-se, então, se os países industrializados concentram maior número de patentes em virtude do efeito de políticas públicas nacionais. Para se esclarecer esse ponto, o EPO examinou os efeitos que a concessão de tarifas incentivadas (feed-in tariffs), bem como os investimentos governamentais em pesquisa e desenvolvimento exerceram sobre o total de prioridades requisita- 
das por Japão, Estados Unidos e Alemanha. Não foi possível inferir uma relação causal constante entre aumento da atividade de patenteamento e políticas públicas governamentais. Estas ora tiveram efeitos positivos, ora foram ineficazes, resultado que variou conforme o país e o setor tecnológico envolvido.

Por outro lado, surpreende que países considerados emergentes, como a China e o Brasil, tenham um nível de patenteamento tão baixo. Isso pode ser indicativo de que a economia de tais países cresce com foco mais na produção material do que na criação intelectual. Contudo, esse modelo de crescimento é criticado justamente por causa da pequena taxa de inovação local. O problema é que se cria uma dicotomia entre países produtores e países exportadores de conhecimento, com aqueles dependendo da transferência da tecnologia criada por estes.

Examinando a tendência de patenteamento de CETs em mais de um país, repetiu-se o resultado acima. Novamente, a atividade se concentrou nos países industrializados, seja com relação à origem do titular da patente primitiva, seja com relação ao destinatário do requisito de prioridade. Os líderes, tanto no primeiro caso, quanto no segundo, foram Japão, Estados Unidos e Alemanha. O pequeno número de patentes originárias da China e do Brasil é reflexo do pequeno destaque que a criação intelectual tem em suas economias. Além disso, em ambos predominaram os depósitos de patentes por países industrializados, o que converge com a conclusão de que há dependência tecnológica.

\section{III.IV. Questionário sobre licenciamento}

A etapa anterior mostrou que os países industrializados não costumam patentear, nos países em desenvolvimento, as CETs que criam. A justificativa para esse modelo de disseminação foi buscada nos próprios detentores de tecnologias verdes. Assim, I60 organizações, quase todas sediadas em países industrializados, responderam a um questionário sobre suas atividades de licenciamento.

As respostas evidenciaram que a vontade de licenciar tecnologias para países em desenvolvimento não reflete o real nível de transferência. As organizações se mostraram dispostas a negociar com esses países e, sobretudo, a flexibilizar os termos do contrato de licenciamento em virtude da menor capacidade financeira do receptor. Porém, indicaram inúmeros obstáculos à sua efetivação, desde a dificuldade de identificar um parceiro local adequado até os elevados custos de transação.

O seleto grupo dos países emergentes foi o principal destinatário dos acordos de licenciamento ou de outras atividades de comercialização de di- 
reitos de propriedade intelectual realizados pelas organizações. Assim, Brasil, Rússia, Índia e China concentraram 64\% dos negócios. Isso corrobora a conclusão da etapa anterior, isto é, a economia desses países cresce com foco na produção e depende da transferência de tecnologias desenvolvidas por países industrializados.

Ademais, solicitou-se aos participantes que elencassem, por ordem de importância, os fatores determinantes da decisão de celebrar um contrato de licenciamento. O regime de proteção à propriedade intelectual adotado pelo país receptor foi considerado importante por $82 \%$ das organizações. Porém, não se trata de fator isolado, já que também foram apontados como relevantes: capacidade científica, infraestrutura e capital humano; condições de mercado favoráveis; e clima de investimento favorável.

\section{III.v. Conclusões}

Em suma, do estudo realizado pelo EPO, junto com o UNEP e o ICTSD, pode-se extrair as seguintes conclusões:

i. Acordos internacionais, associados em alguns casos a políticas públicas nacionais, são capazes de estimular o desenvolvimento e a difusão de tecnologias verdes;

ii. os órgãos nacionais responsáveis pelo depósito de patentes devem elaborar taxonomias específicas para as tecnologias verdes. Dados melhor organizados e com acesso fácil incentivam a atividade tanto de formuladores de políticas públicas quanto de inventores;

iii. as patentes de tecnologias verdes estão concentradas nos países industrializados;

iv. a transferência de tecnologias verdes para os países em desenvolvimento é pequena e se concentra no grupo dos emergentes (Brasil, Rússia, Índia e China). A economia destes cresce com foco na produção de bens e é dependente da transferência de tecnologias desenvolvidas pelos países industrializados;

v. os detentores de tecnologias verdes têm vontade de aumentar a quantidade de contratos de licenciamento para países em desenvolvimento e estão dispostos a negociar termos mais flexíveis; e

vi. o sistema de proteção à propriedade intelectual é fator determinante da decisão de transferir tecnologia para outro país. 


\section{O Projeto Patentes Verdes}

Nos últimos anos, o Brasil assumiu papel de destaque em diversos campos. Quanto à economia, é considerado um país emergente, grande exportador de produtos básicos. ${ }^{\text {Io }}$ Contudo, a criação de tecnologias locais tem pouco papel nesse modelo, o que torna o Brasil dependente do conhecimento estrangeiro.

A situação adquire particular relevância quando se considera o problema das mudanças climáticas. Diante da perspectiva de que um novo acordo internacional vincule os países emergentes a metas de redução de emissão de gases de efeito estufa, o incentivo às tecnologias verdes torna-se prioridade. Torna-se fundamental a atuação do Estado, seja para estimular o inventor local, seja para atrair a transferência de tecnologias estrangeiras. Assim, os direitos de propriedade intelectual podem ser objeto de uma política pública adotada pelo governo.

É esse o fundamento do Projeto Patentes Verdes, que será descrito a seguir e, depois, relacionado às conclusões do estudo anteriormente analisado. Com base em programas semelhantes adotados em outros países, ${ }^{\text {II }}$ o INPI propôs o Projeto Patentes Verdes, cujo lançamento ocorreu em junho de 20I2, durante a Conferência das Nações Unidas sobre Desenvolvimento Sustentável (Rio+20). O programa piloto do projeto teve início em I7 de abril de 2012 e, no momento, está em sua segunda fase. Tem por objetivo reduzir substancialmente o prazo de concessão de patentes relativas a tecnologias verdes. Em conjunto com a aceleração do exame do pedido de depósito, o INPI pretende utilizar o Projeto para identificar as tecnologias verdes. Com isso, espera fomentar o investimento e a inovação na área, aumentando o total de patentes verdes. ${ }^{\text {I2 }}$

Percebe-se que o Projeto Patentes Verdes está em consonância com as conclusões obtidas no estudo analisado anteriormente. Trata-se de uma política pública nacional que instrumentaliza os direitos de propriedade intelectual com vistas ao desenvolvimento econômico e social. A redução do tempo

Io Segundo dados do governo, os produtos básicos responderam por 47,5\% das exportações brasileiras entre janeiro e junho de 20II. Cf. BRASIL. Ministério do Desenvolvimento, Indústria e Comércio Exterior. Balança Comercial Brasileira: dados consolidados. Brasília, 20II, p. I5. Disponível em: <http:// www.mdic.gov.br/arquivos/dwnl_I3I220I939.pdf>. Acesso em: 08 jan. 2012.

II Austrália, Ghina, Japão, Coreia do Sul, Reino Unido e Estados Unidos implementaram programas para agilizar a concessão de patentes relativas à tecnologias verdes.

12 Gf. o portal do Projeto Patentes Verdes no site do INPI. Disponível em <http://www.inpi.gov.br/ portal/artigo/patentes_verdes>. Acesso em 08 out. 2013 
de concessão da patente implica a diminuição dos custos de transação. Além disso, resulta no fortalecimento do regime de tutela da propriedade intelectual, já que o titular esperará menos para exercer seu direito de exclusivo. Dessa forma, torna-se mais atrativa a transferência de tecnologias verdes para o Brasil. Está de acordo, portanto, com as conclusões do EPO, do ICTSD e do UNEP. Falta, contudo, adotar uma classificação exclusiva para as tecnologias verdes, pois o tradicional sistema IPC não contempla categorias satisfatórias para essa nova área.

\section{Referências bibliográficas}

AMORIM, Maria. Patentes Verdes. Instituto Nacional da Propriedade Industrial (INPI) estuda implantação de projeto para acelerar o registro de patentes de baixa emissão de tecnologias carbono. Revista do CREA-RJ, Rio de Janeiro, n. 88, p. I4-I7, jun./jul. 20II. Disponível em: <http://www.crea-rj.org.br/wp-content/ uploads/20II/o8/RevistaCrea88_WEB.pdf>. Acesso em: O8 jan. 2012.

BALAZINA, Afra. Tempo para patente verde deve cair. O Estado de S. Paulo, São Paulo, 6 nov. 20II. Caderno Vida, p. A28. Disponível em: <http://www. estadao.com.br/noticias/impresso,tempo-para-patente-verde-deve-cair-,795I39, O.htm>. Acesso em: 08 jan. 2012.

BARBOSA, Denis B. Uma introdução à propriedade intelectual. 2. ed. revista e atualizada. Rio de Janeiro: Lumen Juris, 2003. Disponível em: <http://www.denisbarbosa. addr.com/arquivos/livros/umaintro2.pdf>. Acesso em: 24 dez. 201 I.

EUROPEAN PATENT OFFIGE; INTERNATIONAL GENTER FOR TRADE AND SUSTAINABLE DEVELOPMENT; UNITED NATIONS ENVIRONMENT PROGRAMME. Final Report: Patents and Clean Energy: bridging the gap between evidence and police. München, 20IO. Disponível em: <http:// documents.epo.org/projects/babylon/eponet.nsf/o/cc5da4bi68363477cI 2577ado 0547289/\$FILE/patents_clean_energy_study_en.pdf>. Acesso em O8 jan. 2012.

UNITED NATIONS. United Nations Framework Convention on Climate Change. New York, I992. Disponível em: <http://unfccc.int/resource/docs/convkp/conveng. pdf $>$. Acesso em: 08 jan. 2012.

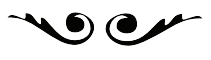

Adriana Regina Sarra de Deus - Graduanda da Faculdade de Direito pela Universidade de São Paulo. adriana.deus@usp.br; dri_sarra@hotmail.com 